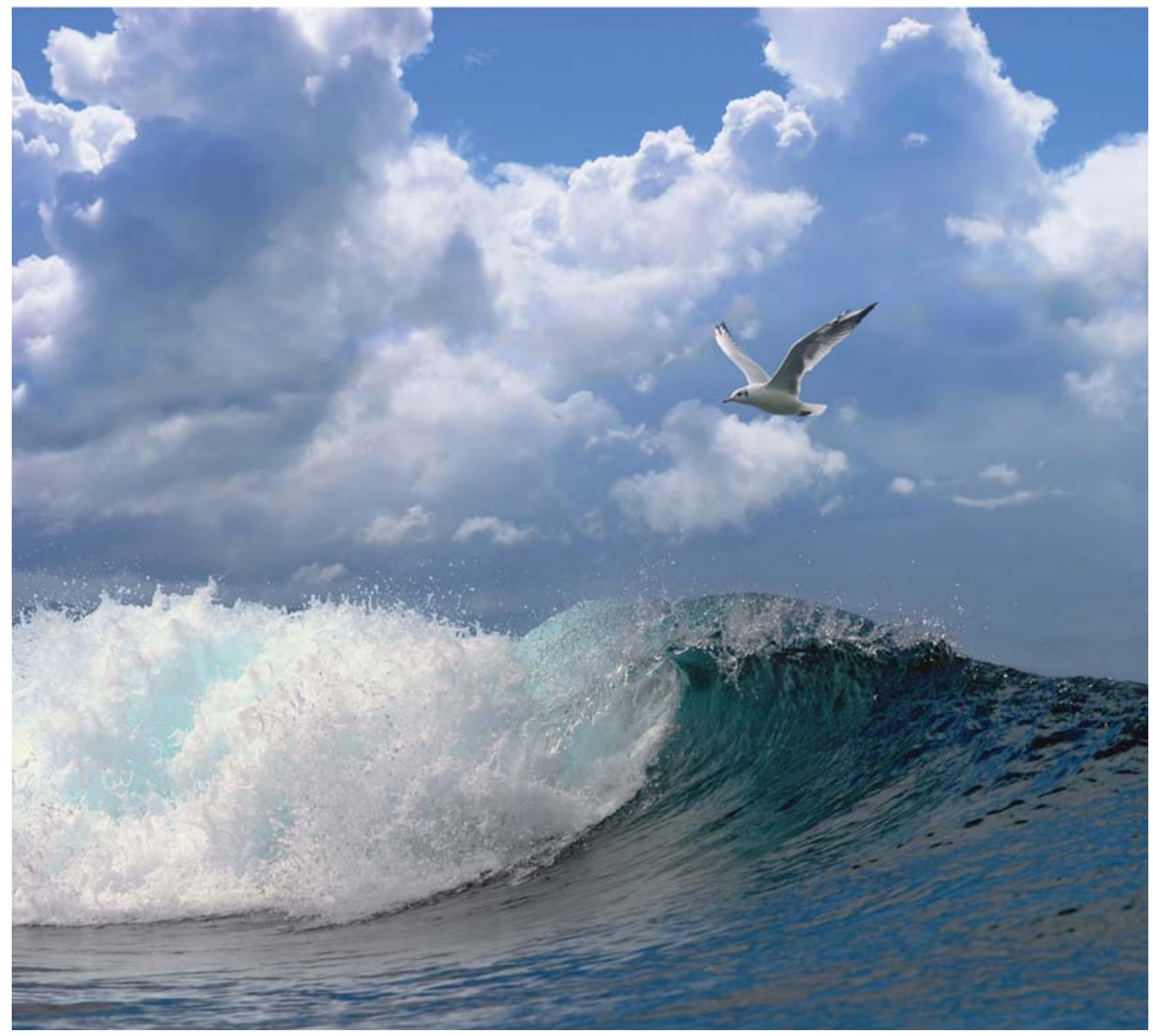

\title{
Plastics in mosselen
}





\section{Plastics in mosselen}

Auteur(s): $\quad$ E.M. Foekema ${ }^{1,2}$, M.J. van den Heuvel-Greve ${ }^{1}$, A.J. Murk ${ }^{2}$ en A.A. Koelmans ${ }^{1,3}$

Publicatiedatum: 4 augustus 2017

${ }^{1}$ Wageningen Marine Research

${ }^{2}$ Wageningen University, Marine Animal Ecology group

${ }^{3}$ Wageningen University, Aquatic Ecology and Water Quality Management group

Wageningen Marine Research Den Helder, augustus 2017

VERTROUWELIJK Nee

Wageningen Marine Research rapport C055/17 
Foekema E.M., M.J. van den Heuvel-Greve ${ }^{1}$, A.J. Murk ${ }^{2}$ en A.A. Koelmans ${ }^{1,3}, 2017$. Plastics in mosselen; . Wageningen Marine Research Wageningen UR (University \& Research centre), Wageningen Marine Research rapport C055/17.

Keywords: Plastics mussel.

Opdrachtgever: Stichting Kwaliteitszaken Schelpdieren,

T.a.v. Wouter van Zandbrink

Dregweg 2

4401 LD Yerseke

Email: info@zandbrink.nl

Dit rapport is vanaf 2 maanden na publicatie gratis te downloaden van

https://doi.org/10.18174/419680

Wageningen Marine Research verstrekt geen gedrukte exemplaren van rapporten.

Wageningen Marine Research Wageningen UR is ISO 9001:2008 gecertificeerd.

(C) 2017 Wageningen Marine Research Wageningen UR

Wageningen Marine Research, onderdeel van Stichting Wageningen Research KvK nr. 09098104,

IMARES BTW nr. NL 8113.83.696.B16.

Code BIC/SWIFT address: RABONL2U

IBAN code: NL 73 RABO 0373599285
De Directie van Wageningen Marine Research is niet aansprakelijk voor gevolgschade, noch voor schade welke voortvloeit uit toepassingen van de resultaten van werkzaamheden of andere gegevens verkregen van Wageningen Marine Research opdrachtgever vrijwaart Wageningen Marine Research van aanspraken van derden in verband met deze toepassing.

Dit rapport is vervaardigd op verzoek van de opdrachtgever hierboven aangegeven en is zijn eigendom. Niets uit dit rapport mag weergegeven en/of gepubliceerd worden, gefotokopieerd of op enige andere manier gebruikt worden zonder schriftelijke toestemming van de opdrachtgever. 


\section{Inhoud}

Samenvatting

$\begin{array}{llr}1 & \text { Inleiding } & 5\end{array}$

$\begin{array}{lll}1.1 & \text { Productie van plastics } & 5\end{array}$

$2 \quad$ Plastics in milieu $\quad 6$

2.1 Bronnen van plastic afval in zee 6

$\begin{array}{lll}2.2 & \text { Soorten plastic en formaten } & 7\end{array}$

$\begin{array}{ll}2.3 \text { Hoeveelheden plastic in het milieu } & 7\end{array}$

$3 \quad$ Milieurisico's van mariene plastics $\quad 10$

3.1 Macro-plastics $r$

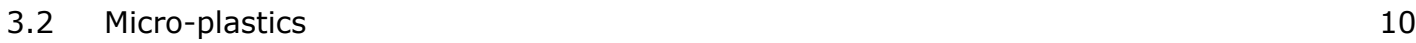

$\begin{array}{ll}3.3 & \text { Nano-plastics } \\ 3.4 & 10\end{array}$

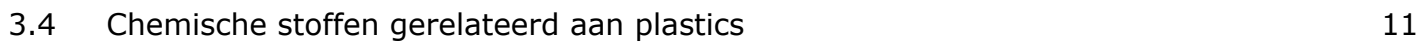

$4 \quad$ Plastics in mosselen $\quad 12$

4.1 Opname van plastic deeltjes door mosselen 12

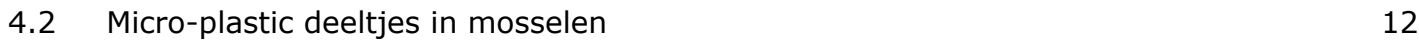

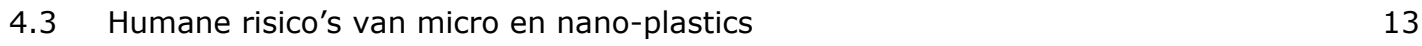

$\begin{array}{lll}4.4 & \text { Blootstelling via mosselen en andere bronnen } & 14\end{array}$

$5 \quad$ Conclusie $r \begin{aligned} & 15\end{aligned}$

$6 \quad$ Samenvatting in vraag en antwoord $\quad 17$

$\begin{array}{lll}6.1 & \text { Geschiedenis fabricage en gebruik van plastic } & 17\end{array}$

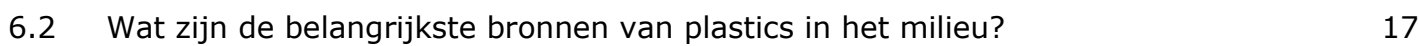

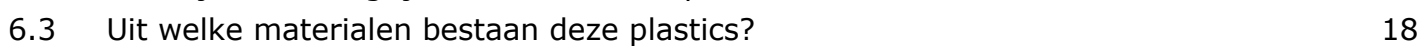

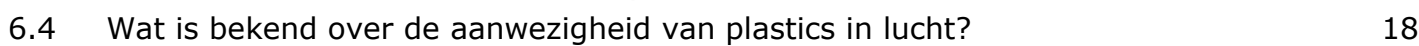

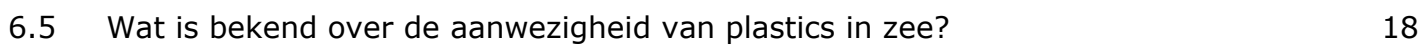

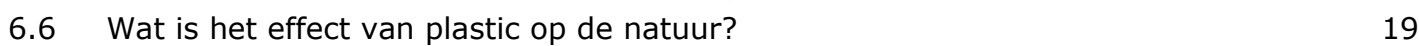

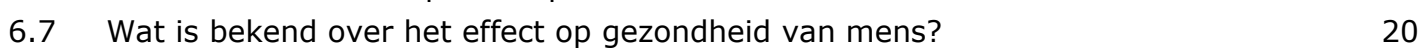

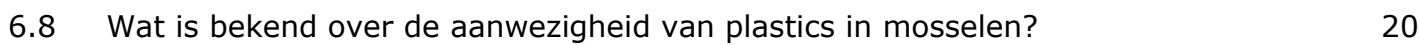

6.9 Hoe worden plastics opgenomen door mosselen en worden ze ook weer uitgescheiden? $\quad 21$

6.10 Kunnen mosselen plastics kwijtraken door verwateren (depuratie)? 22

6.11 Wat is het risico dat plastics uit geconsumeerde mosselen de darmwand van de mens passeren? $\quad 22$

6.12 Wat is het risico voor human health als mosselen met plastics worden geconsumeerd $\begin{array}{ll}\text { (expert judgement)? } & 22\end{array}$

$\begin{array}{llr}7 & \text { Referenties } & 23\end{array}$

$8 \quad$ Kwaliteitsborging $r 25$

$\begin{array}{lr}\text { Verantwoording } & 25\end{array}$ 


\section{Samenvatting}

Plastic afval is in verschillende formaten aanwezig in het zeemilieu. Afbraak vindt niet of nauwelijks plaats, maar het plastic valt wel uiteen in steeds kleinere stukjes. Mosselen kunnen plastic stukjes tussen 5 en 40 micrometer groot uit het water filteren. Hoewel de mossel een deel van dit microplastic als oneetbaar herkent en niet inslikt, kunnen plastic stukjes in het maagdarmkanaal van de mossel terecht komen. De European Food Safety Authority (EFSA) schatte in 2016 dat een portie mosselen tot 7 microgram aan plastic kan bevatten. Verschillende onderzoekers rapporteren de aanwezigheid van microplastics in (consumptie)mosselen waarbij de concentraties variëren tussen 0,1 en 13 deeltjes per gram mosselvlees. Het is onduidelijk of deze variatie daadwerkelijke verschillen tussen mosselen/locaties weergeeft of het gevolg is van verschillende onderzoeksmethoden.

De grotere plastic deeltjes worden nauwelijks vanuit het spijsverteringskanaal opgenomen en verlaten als onverteerbaar deeltjes het lichaam op natuurlijke wijze.

Het is niet bekend in welke mate hele kleine plastic deeltjes (nano-deeltjes, <100 nm) aanwezig zijn in mosselen, of in ander voedsel. De huidige analysetechnieken zijn niet toereikend om deze extreem kleine deeltjes te detecteren. Ook is onvoldoende kennis beschikbaar om vast te stellen of deze nanodeeltjes gezondheidsrisico's opleveren.

Er is geen reden om aan te nemen dat consumptie van mosselen, als onderdeel van een normaal menu, een substantiële bijdrage zal leveren aan de blootstelling van mensen aan nano- en microplastics ten opzichte van andere bronnen, waaronder huisstof.

Hoofdstuk 6 van dit rapport bevat een uitgebreide samenvatting op basis van een aantal veel gestelde vragen over plastic in het mariene milieu en in mosselen in het bijzonder. 


\section{$1 \quad$ Inleiding}

Met regelmaat verschijnen er berichten in de media over de aanwezigheid van micro-plastics in schelpdieren en mogelijke risico's hiervan voor de consument. Naar aanleiding van deze berichten heeft Stichting Kwaliteitszaken Schelpdieren aan Wageningen Marine Research gevraagd om een beknopt overzicht te geven van de huidige kennis over herkomst, aanwezigheid en effecten van plastics in het milieu op basis van bestaande wetenschappelijke literatuur, en dit vervolgens toe te spitsen op de aanwezigheid van plastics in consumptie mosselen en de mogelijke risico's voor consumenten.

\subsection{Productie van plastics}

De grootschalige productie van plastics is vooral na de Tweede Wereldoorlog op gang gekomen en is sindsdien wereldwijd gestegen tot meer dan 300 miljoen ton per jaar (gegevens 2013 en 2015 in EPA 2016). Plastic is een verzamelnaam voor materialen bestaande uit polymeren met als basis grondstof aardolie. Doordat er verschillende soorten plastics kunnen worden geproduceerd met specifieke eigenschappen, en omdat de productie van plastics relatief goedkoop is, is het niet verwonderlijk dat deze materialen op zeer grote schaal worden geproduceerd en gebruikt.

Recentelijk worden ook plastics uit andere, veelal plantaardige materialen geproduceerd. In sommige gevallen mogen deze plastics aangemerkt worden als biologisch afbreekbaar omdat ze in composteerinstallaties kunnen worden afgebroken. In deze installaties zijn de omstandigheden voor het afbraakproces optimaal, zo wordt bijvoorbeeld een temperatuur van rond $60^{\circ} \mathrm{C}$ gehandhaafd. Onder natuurlijke omstandigheden, zoals in zee, is de afbreekbaarheid ook van deze plastics echter zeer beperkt (Nauendorf et al., 2016). 


\section{$2 \quad$ Plastics in milieu}

Plastic wordt aangetroffen op land, in zoet- en zoutwater en als fijn stof in de lucht. Deze review is gericht op consumptie mosselen, en dus op zoutwater.

De aanwezigheid van plastics in lucht heeft weliswaar geen directe relatie met mosselen, maar vormt wel een aandachtpunt bij onderzoek naar micro-plastics in zee(dieren). Synthetische vezels in huisstof en lucht, afkomstig van kleding, stoffering en meubels, vallen namelijk ook onder de noemer 'microplastics'. Zeer recent zijn voor het eerst concentraties van vezels in de lucht bepaald (Dris et al., 2017). Binnenshuis zijn tussen 1 en 60 vezels per $\mathrm{m}^{3}$ aangetroffen en buitenshuis varieerde dit tussen 0,3 en 1,5 . Ongeveer één derde van de vezels bestond uit synthetisch materiaal.

Ook is vastgesteld dat synthetische vezels in een laboratoriumomgeving aanwezig zijn en onderzoeksmonsters uit zee kunnen vervuilen. Daarom is het noodzakelijk om uitgebreide maatregelen te nemen om vervuiling van de monsters (zowel in het veld als in het lab) tegen te gaan wanneer onderzoek naar plastic vezels wordt uitgevoerd (Foekema et al., 2013; Torre et al.,2016; Hermsen et al., 2017). In het recent door ICES opgestelde monitoringsprotocol voor micro-plastics in vissen en schelpdieren worden vezels kleiner dan $5 \mathrm{~mm}$ bewust buiten beschouwing gelaten, omdat het in de praktijk zo moeilijk is om verontreiniging van het monster via de lucht te voorkomen (ICES 2015).

Onderzoeksresultaten waarbij wel fijne synthetische vezels worden gerapporteerd zijn dus alleen betrouwbaar als zeer scherpe maatregelen zijn genomen en gerapporteerd om vervuiling via de lucht tegen te gaan. Uit gepubliceerde gegevens is niet altijd duidelijk of dat ook het geval was.

\subsection{Bronnen van plastic afval in zee}

Een belangrijk deel van de van plastic geproduceerde producten wordt maar kort gebruikt als verpakkingsmateriaal of wegwerpartikel, waardoor plastic een substantieel deel vormt van het huishoudelijk afval. Omdat niet al het afval effectief wordt verzameld en verwerkt, komt er ook veel in het milieu terecht. Getransporteerd door de wind of via rivieren, eindigt een deel hiervan in zee.

Plastic pellets met een diameter tussen de 1 en $5 \mathrm{~mm}$ zijn de grondstof voor de plastic-verwerkende industrie. Deze pellets worden met regelmaat in het milieu aangetroffen (EPA, 2016). Daarnaast worden plastic deeltjes, de zogenaamde microbeads $(<1 \mathrm{~mm})$, verwerkt in verschillende verzorgingsproducten. Ook komen kunststof vezels vrij bij het wassen van kleding.

Rioolwaterzuiveringen worden daarom als potentiele bron gezien voor micro-plastics in het oppervlaktewater. In hoeverre deze een belangrijke bron vormen is nog niet goed onderzocht. Resultaten van uitgevoerde onderzoeken lopen tevens sterk uiteen, van $<1 / \mathrm{m}^{3}$ (Carr el al.,2016) tot $51000-81000 / \mathrm{m}^{3}$ (Leslie et al., 2017). De reden van deze enorme verschillen is onduidelijk. Het kan het gevolg zijn van verschillen tussen de onderzochte rioolwaterzuiveringen en/of in de (kwaliteit van de) verwerkingsmethoden van de monsters.

Van de plasticdeeltjes die in het oppervlaktewater terecht komen zal naar verwachting een deel in het slib van het binnenwater bezinken (Besseling et al., 2017a). De rest kan uiteindelijk de zee bereiken. Naast bovengenoemde bronnen vormen in het zoutwater milieu zelf nylon visnetten een belangrijke bron van plastic, zowel door verlies als door afslijten van fragmenten tijdens het gebruik in de bodemvisserij (http://www.vispluisvrij.nl).

Volgens een ruwe schatting komt er jaarlijks tussen de 5 en 13 miljoen ton plastic in zee terecht, afkomstig van allerlei bronnen wereldwijd (gebaseerd op schatting voor 2010 Jambeck et al., 2015, in EPA, 2016). 


\subsection{Soorten plastic en formaten}

De meest typen plastic en hun vormen, die in zee zijn aangetroffen, zijn weergegeven in Tabel

\section{Error! Reference source not found.}

\section{Tabel 1}

Overzicht van de meeste, in zee aangetroffen typen plastics en enkele specifieke toepassingen (o.b.v. Hidalgo-Ruz et al.,2012 en Andrady 2012).

\begin{tabular}{|l|l|}
\hline Soort plastic & Bekende toepassingen \\
\hline Polyethyleen & Wegwerptasjes/zakken, opslagcontainers/-vaten, emmers, \\
Polypropyleen & verpakkingsmateriaal \\
Polystyreen & Touw, flessendoppen, microbeads/pellets \\
Polyamide (nylon) & Verpakkingsmateriaal, isolatiemateriaal, rietjes, wegwerp \\
Polyester & bekers \\
Acryl & Touw, visnetten \\
Polyvinyl chloride (PVC) & Kleding, glass-fiber constructies \\
Polyethyleen terephtalate (PET) & Kleding (vezels) \\
\hline
\end{tabular}

Bij milieuonderzoek worden de aangetroffen plastics in verschillende groepen ingedeeld op basis van grootte. Hiervoor wordt in het algemeen de volgende indeling gebruikt:

Macro-plastics: $>5 \mathrm{~mm}$

Micro-plastics: $<5 \mathrm{~mm}$

Nano-plastics: $<100 \mathrm{~nm}$

Veel plastic komt in het milieu terecht als grof afval, dus als macro-plastic dat vaak vele malen groter is dan de ondergrens van $5 \mathrm{~mm}$. Onder invloed van ultraviolet licht, schuren en beweging kan dit uiteenvallen tot kleinere deeltjes (EPA 2016). Hiernaast worden micro-plastics gerapporteerd als textielvezels, slijtage van visnetten, microbeads uit verzorgingsproducten (zoals scrub-crèmes en tandpasta), en pellets (grondstoffen) voor de plastic-verwerkende industrie.

Het fragmenteren van het plastic zal niet stoppen bij het micro-formaat. Daarom wordt algemeen aangenomen dat ook nano-plastic deeltjes in het milieu aanwezig zijn. Dit is echter nog niet aangetoond, omdat er op dit moment nog geen methoden bestaan om de aanwezigheid van deze extreem kleine deeltjes in het milieu aan te tonen.

Nano-plastics kunnen ook direct door menselijke activiteiten ontstaan. Bijvoorbeeld als vezels bij het reinigen en drogen van synthetische kleding, het thermisch snijden van polystyreen 'piepschuim' en het gebruik van 3-D printers (Koelmans et al., 2015). Met uitzondering van de kledingvezels die in de wasmachine ontstaan en via het rioolwater worden afgevoerd, zullen veel van deze nano-plastics aanvankelijk via de lucht verspreid worden als onderdeel van fijn stof. Omdat het nog niet mogelijk is deze deeltjes te detecteren in het milieu, is onduidelijk in welke mate zij voorkomen en zich in het milieu verspreiden.

\subsection{Hoeveelheden plastic in het milieu}

Plastic afval is alom aanwezig in het milieu. De gerapporteerde hoeveelheden lopen sterk uiteen per locatie en per gebruikte onderzoeksmethode. In Tabel 2 is een overzicht gegeven van de in 2012 beschikbare data over de hoeveelheden afval langs de kustlijn en op de zeebodem in Europa. Het betreft hier de grotere afval items. Gemiddeld bestond 60\% hiervan uit plastics (Rippen \& Foekema, 2012). 


\section{Tabel 2}

Minimale en maximale gerapporteerde hoeveelheden marien afval aangetroffen langs de kustlijn of opgevist nabij de zeebodem (opgevist) in de Europese zeeën. Gemiddeld bestond $60 \%$ uit plastic. (Rippen \& Foekema, 2012)

\begin{tabular}{|c|c|c|c|c|}
\hline Locatie & $\begin{array}{c}\mathrm{Kg} / 100 \text { m } \\
\text { kustlijn }\end{array}$ & $\begin{array}{c}\text { Items/ 100m } \\
\text { kustlijn }\end{array}$ & $\begin{array}{c}\mathrm{Kg} / \mathrm{km} 2 \\
\text { Zeebodem }\end{array}$ & $\begin{array}{l}\text { I tems/ kg } \\
\text { Zeebodem }\end{array}$ \\
\hline Baltische zee & $10-2000000$ & $21-1200$ & $2300-40000000$ & 126 \\
\hline Zwarte Zee & $0.03-140$ & 217 & $0.3-102250$ & $7-1320$ \\
\hline Middellandse Zee & $3-314$ & $6-23100$ & $2-580644$ & $2-3712$ \\
\hline Noordzee $\# 4$ & $4-3000$ & $6-712$ & $6566-9448$ & $300-50500$ \\
\hline \multicolumn{5}{|c|}{$\begin{array}{l}\text { \#1 HELCOM } 2007 \\
\text { \#2 BSC 2009; Topcu 2010; Guneroglu } 2010 \\
\text { \#3 UNEP(DEPI)MED 2011; Galil 1995; Gabrielides et al. 1991; Galgani et al. 1995; Katsanevakis 2004; } \\
\text { Stefatos et al. 1999; Koutsodendris et al. 2008; Martinez-Ribes et al., } 2007 \\
\text { \#4 UNEP(DEPI)MED 2011; OSPAR 2009; Thiel et al. 2011; Mordecai et al. } 2011\end{array}$} \\
\hline
\end{tabular}

\section{Tabel 3}

Maximale aantallen deeltjes micro-plastics (in elk geval $>65 \mu \mathrm{m}$ ) gerapporteerd voor verschillende regio's (gegevens uit GESAMP, 2015 aangevuld met Frias et al.,2014, Desforges et al.,2014 en Cózar et al.,2017). De datasets waarvoor alleen aantallen per $\mathrm{km} 2$ werden gerapporteerd zijn ter indicatie omgerekend naar aantallen per $\mathrm{m}^{3}$ met de aanname dat er een waterdiepte van $10 \mathrm{~cm}$ werd bemonsterd $\left(1 \mathrm{~km} 2=100.000 \mathrm{~m}^{3}\right)$.

\begin{tabular}{|c|c|c|c|}
\hline Locatie & $\mathbf{n} / \mathbf{k m}^{2}$ & $\mathbf{n} / \mathbf{m}^{3}$ & Referentie \\
\hline North Sea & Geen data & 0,05 & Thompson et al.,2004 \\
\hline Western North Atlantic & Geen data & 14,1 & Carpenter etal 1972 \\
\hline Eastern North Atlantic & Geen data & 0,116 & Collignon etal 2012 \\
\hline Mediterranean Sea & Geen data & 0,94 & Fossi et al. 2012 \\
\hline Western North Atlantic & Geen data & 0,04 & Frias et al. 2014 \\
\hline North Eastern Pacific & Geen data & 9180 & Desforges et al.,2014 \\
\hline Locatie & $\mathbf{n} / \mathbf{k m}^{2}$ & $\begin{array}{c}n / \mathbf{m}^{3} \text { berekend } \\
\text { (niet gerapporteerd) }\end{array}$ & referentie \\
\hline Western North Atlantic & 12080 & 0,12 & Carpenter \& Smith 1972 \\
\hline Western North Atlantic & 5466 & 0,05 & Colton et al.,1974 \\
\hline Western North Atlantic & 20328 & 0,20 & Law et al.2010 \\
\hline North Pacific & 34000 & 0,34 & Wong et al. 1974 \\
\hline North Pacific & 80 & 0,001 & Day and Shaw 1987 \\
\hline North Pacific & 3370 & 0,03 & Day and Shaw 1987 \\
\hline North Pacific & 96100 & 0,96 & Day and Shaw 1987 \\
\hline Eastern North Pacific & 969777 & 9,70 & Moore et al. 2001 \\
\hline Eastern North Pacific & 156800 & 1,57 & Law et al. 2014 \\
\hline Western North Pacific & 174000 & 1,74 & Yamashita \& Tanimura 2007 \\
\hline Australia & 4256 & 0,04 & Reisser et al. 2014 \\
\hline Arctic Ocean & 320000 & 3,20 & Cozar et al., 2017 \\
\hline
\end{tabular}

De hoeveelheid microplastics in zeewater worden veelal gerapporteerd in aantal per $\mathrm{m}^{3}$ of, wanneer het oppervlaktemonsters betreft, in aantallen per $\mathrm{km}^{2}$. In Tabel 3 zijn de beschikbare gegevens samengevat. Ter indicatie zijn gegevens per $\mathrm{km}^{2}$ omgerekend naar aantallen per $\mathrm{m}^{3}$, waarbij ervan uitgegaan is dat er standaard een laagdiepte van $10 \mathrm{~cm}$ is bemonsterd. Op het merendeel van de locaties wordt minder dan 1 micro-plastic deeltje per $\mathrm{m}^{3}$ water aangetroffen.

Hogere concentraties van 14 (gerapporteerd als $\mathrm{n} / \mathrm{m}^{3}$ ), 9,7 en 3,2 (beiden gerapporteerd als $\mathrm{n} / \mathrm{km}^{2}$ ) werden gemeten in gebieden die bekend staan als verzamelplaats van plastics. Een opvallende uitschieter vormt de dataset van Desforges et al.,(2014) die meer dan 9000 plastic deeltjes per $\mathrm{m}^{3}$ aantroffen in de North Eastern Pacific, in een zogenaamde 'gyre' waarin organisch materiaal en plastic 'gevangen' zit in een ronddraaiende stroming. Hierbij werd een echter een fijner net (65 micrometer) 
gebruikt dan bij de andere studies (doorgaans ca 300 micrometer). Dit suggereert dat kleinere plastic deeltjes in grotere aantallen aanwezig zijn. Er zijn echter geen gegevens bekend over de aanwezigheid van kleinere plastic deeltjes in zee ( $<65$ micrometer), en de allerkleinste (nano)deeltjes zijn technisch nog niet aan te tonen in milieumonsters. 


\section{Milieurisico's van mariene plastics}

\subsection{Macro-plastics}

Afhankelijk van het formaat en de vorm kunnen macro-plastics in het milieu risico's opleveren voor organismen die erin verstrikt raken (visnetten, vislijn, verpakkingsmaterialen) of het inslikken. Dit inslikken kan onbedoeld gebeuren, zoals bij een grote filterfeeder als de bultrug (Besseling et al., 2015) waarschijnlijk het geval is, of bewust plaatsvinden, omdat het plastic als voedsel wordt gezien. Zo wordt vermoed dat zeeschildpadden plastic zakken opeten, omdat ze drijvend in het water op kwallen lijken (Takuya et al., 2016) en pikken Noorse Stormvogels en albatrossen drijvend plastic op van het wateroppervlak omdat ze dat waarschijnlijk voor voedsel aanzien (van Franeker en Law, 2015). Ingeslikte kleinere plastic deeltjes kunnen het lichaam via de natuurlijke weg verlaten, maar grotere stukken plastic kunnen in het maag-darmkanaal verstoppingen veroorzaken. In theorie zou een gedeeltelijk met plastic gevulde maag de eetlust kunnen remmen. In veldonderzoek zijn tweemaal correlaties aangetoond tussen de hoeveelheid in het maagdarmkanaal aanwezige plastic en de conditie (lichaamsgewicht) van zeevogels (Furness, 1985; Spear et al., 1995 in overzicht in GESAMP, 2015).

\subsection{Micro-plastics}

Micro-plastics zullen voor grotere organismen weinig bedreiging vormen. Zolang het maag-darmkanaal passage van de plastic deeltjes toelaat, zal het plastic het lichaam passeren als elk ander onverteerbaar deeltje. Hierbij is uiteraard de verhouding lichaamslengte en het formaat van het plastic deeltje van belang. In het algemeen zijn micro-plastics te groot om de darmwand te passeren of om via de kieuwen of longen in de bloedbaan en door het lichaam te worden verspreid. Toch suggereren laboratorium testen dat plasticdeeltjes tot $150 \mu \mathrm{m}$ groot in staat zijn cellagen te passeren (Van Cauwenberghe, 2015). Deze deeltjes, die te groot zijn om cellen binnen te dringen zijn niet in staat het lymfesysteem te passeren en worden via de milt afgevoerd (Bouwmeester et al.,2015). Dergelijke testen zijn vooral gedaan met in het laboratorium gekweekte cellen zonder de beschermende epitheliale slijmlaag die als functie heeft om grotere deeltjes af te vangen. Voor zilverdeeltjes groter dan $200 \mathrm{~nm}$ blijkt zo'n intacte slijmlaag een barrière te vormen (Georgantzopoulou et al., 2016). Of dit ook geldt voor plasticdeeltjes van dezelfde grootte (dus de kleinste fractie van de micro-plastics en nano-plastics) is onduidelijk en wordt verder besproken in de volgende paragraaf over nano-plastics.

In laboratoriumstudies met hoge doseringen micro-plastics in de $\mu \mathrm{m}$-range zijn effecten op organismen aangetoond. Deze zijn doorgaans het gevolg van fysische reacties. Bijvoorbeeld doordat de aanwezigheid van de zwevende plastic deeltjes de effectieve voedselopname van algenetende soorten als mosselen (Van Cauwenberghe et al. 2012b, 2013a in GESAMP, 2015) en dierlijk plankton (Ogonowski et al.,2016) verminderd, of dat algengroei wordt beperkt doordat de deeltjes de doorval van licht beperken, of de algen doen samenklonteren (Zhang et al., 2017). Zonder uitzondering worden deze effecten gevonden bij concentraties die vele malen hoger liggen dan wat in het milieu tot dusverre is aangetroffen.

\subsection{Nano-plastics}

Dat nano-deeltjes (kleiner dan $100 \mathrm{~nm}$ ) en de kleinste fractie van micro-deeltjes (tot $200 \mathrm{~nm}$ ) celmembranen kunnen passeren en via de bloedbaan in weefsels en organen terecht kunnen komen is voor verschillende materialen aangetoond. De mate waarin dit gebeurd hangt sterk samen met de eigenschappen van de deeltjes waarbij onder andere de lading een belangrijke rol speelt. Waarschijnlijk geldt dit ook voor nano-plastic deeltjes, maar hier bestaat nog nauwelijks inzicht in (Bouwmeester at al., 2015; ESFA 2016).

Opname van deze kleine plastic deeltjes in bloed en weefsel is via laboratoriumonderzoek aangetoond voor schelpdieren, kreeftachtigen en vissen (zie bijv. Koelmans et al.,2015; Da Costa 2016 voor overzichten). In sommige van deze gevallen zijn bij hoge blootstellingen ( $>0.5 \mathrm{mg} / \mathrm{L}$; Koelmans et al., 
2015) ook effecten op ontwikkeling en conditie van het individu vastgesteld. Omdat concentraties aan nano-plastics in het milieu nog niet kunnen worden vastgesteld ${ }_{L}$ is het niet mogelijk deze laboratorium resultaten naar veldsituaties te vertalen. Nano-deeltjes gaan in het algemeen een sterke interactie aan met hun omgeving. Ze klonteren bijvoorbeeld makkelijk samen en plakken aan andere deeltjes in het water. Dit maakt het nog lastiger om resultaten van laboratoriumtesten met doorgaans minder complexe omstandigheden dan het echte milieu door te vertalen naar de veldsituatie (Bundshuh et al.,2016; Koelmans et al., 2015).

\subsection{Chemische stoffen gerelateerd aan plastics}

Slecht afbreekbare verontreinigende stoffen zoals PCBs en Dioxines, kortweg POPs (Persistent Organic Pollutants) lossen nauwelijks in water op. In waterig milieu hechten zij zich aan al dan niet levend organisch materiaal, waarbij ophoping in vooral sedimenten, zwevende deeltjes en vetweefsel (in dieren) optreedt. Door deze eigenschap en door hun persistentie hopen POPs op in de voedselketen. Ondanks dat de productie van de meeste van deze stoffen reeds lang geleden aan banden is gelegd, leiden zij nog steeds tot een verminderd voortplantingssucces bij sommige toppredatoren (Jepson et al.,2016).

Ook hopen POPs makkelijk op in plastic. Gehalten aan POPs in op stranden gevonden plastics pellets verschillen per regio (Ogata et al.,2009). Als dieren dit verontreinigde plastic opeten krijgen zij hiermee ook deze POPs binnen. Of de stoffen van het plastic loskomen, of met het plastic worden uitgepoept hangt onder andere af van de verblijftijd in de darm en de concentratie van de stoffen in het plastic ten opzichte van de concentratie in het lichaam. POPs uit echte prooien die verteerd worden, komen veel makkelijker in de bloedbaan terecht dan POPs die door diffusie uit een stukje plastic moeten vrijkomen. Recent onderzoek laat zien dat de hoeveelheid POPs die dieren onder veldrelevante omstandigheden via plastics binnen krijgen niet of nauwelijks bijdraagt aan de hoeveelheid van dezelfde stoffen die zij via hun normale voedsel opnemen (Koelmans et al., 2016; Ziccardi et al., 2016; Besseling et al., 2017b).

Naast de binding van POPs aan plastics in het milieu, worden bij de productie aan plastics bewust chemische stoffen toegevoegd zoals weekmakers en vlamvertragers. Plastic vormt hiermee wel een bron voor dit soort stoffen naar het milieu. Omdat deze stoffen echter tijdens het gebruik en de afvalfase langzaam uit het plastic verdwijnen, is er vooral risico voor blootstelling van dieren wanneer zij 'vers' plastic inslikken. Zoals beschreven is het merendeel van het verse plastic in het milieu aanwezig in grotere formaten. Dit voorkomt of minimaliseert de kans op inslikken van verse plastics voor veel soorten. Voor grotere soorten geldt opnieuw dat deze stoffen net als de eerder genoemde POPs al aanwezig zijn in het milieu, en dat blootstelling hieraan vooral via het natuurlijk voedsel plaats vindt. 


\section{$4 \quad$ Plastics in mosselen}

\subsection{Opname van plastic deeltjes door mosselen}

Een mossel verzamelt voedsel door algen uit het water te filteren. Een gezonde mossel kan meer dan een liter water per uur filtreren, waarbij met grote efficiëntie deeltjes tussen 5 en 40 micrometer worden verzameld. Micro-plastics van deze grootte in het water zullen dus door een mossel uit het water worden verzameld, samen met algen en bijvoorbeeld in het water aanwezig slib.

Om te kunnen overleven in slibrijk water is een mossel tot op zekere hoogte in staat om uit het verzamelde materiaal eetbare van oneetbare deeltjes te scheiden. De als niet-eetbaar herkende delen worden niet door de mossel ingeslikt, maar als 'pseudo-faeces' uitgescheiden. Aangenomen mag worden dat dit ook met (een deel van) de door de mossel opgenomen micro-plastics zal gebeuren. Onverteerbare delen van het opgenomen voedsel verlaten een mossel na passage van het maagdarmkanaal als faeces. Dit gebeurt bijvoorbeeld met slibdeeltjes bij het verwateren van mosselen. Omdat de filterefficiëntie van een mossel snel afneemt bij deeltjes kleiner dan $4 \mu \mathrm{m}$ zullen individuele nano-plasticdeeltjes door een mossel niet worden verzameld. Nano-deeltjes die zijn samengeklonterd tussen 5 en 40 micrometer kan de mossel wel uit het water filteren (Matson et al., 2015). In een laboratoriumstudie met hoge gehalten nano-plastics bleken de mosselen deze geklonterde nanodeeltjes als pseudo-faeces uit te scheiden (Wegner et al., 2012). Dit betrof 'verse' nano-plastics. Samenklontering met algen of bacteriën zou er voor kunnen zorgen dat de mossel de nano-deeltjes niet als oneetbaar herkend en als voedsel tot zich neemt.

\subsection{Micro-plastic deeltjes in mosselen}

Berichten over plastics in mosselen betreffen altijd micro-plastics. Over de aanwezigheid van nanoplastics in mosselen is om eerder genoemde redenen niets bekend, en macro-plastics zijn te groot om door een mossel te worden opgenomen.

Drie Belgische studies (De Witte et al., 2014, Van Cauwenberghe et al., 2014 en VanderMeersch et al 2015) geven zeer overeenkomstige resultaten met tussen 0.1 en 0.4 micro-plastic deeltje per gram mosselvlees zonder verschil tussen wilde en consumptiemosselen (Tabel 4).

In een onderzoek door Leslie et al., 2017 zijn ruim 40 maal hogere aantallen deeltjes in wilde mosselen gevonden. Het is onduidelijk in hoeverre deze verschillen het gevolg zijn van een verschil in analysemethode. Het feit dat Leslie et al. (2017) meer deeltjes vindt dan De Witte et al. (2014) kan worden veroorzaakt doordat de laatstgenoemde deeltjes kleiner dan $200 \mu \mathrm{m}$ niet onderzocht, terwijl Leslie et al. (2017) een ondergrens van $5 \mu \mathrm{m}$ hanteerde. VanderMeersch et al (2015) en Van Cauwenberghe et al.,(2014) hanteerden een vergelijkbare ondergrens als Leslie et al.(2017). Van Cauwenberghe et al.,(2014) gebruikten een agressieve destructiemethode, waarvan zij aangeven dat hierdoor mogelijk nylonvezels zijn afgebroken. Het feit dat zij geen vezels in hun (blanco) monsters aantreffen zou hier ook op kunnen wijzen, maar kan evengoed duiden op een goede preventie van contaminatie vanuit de werkomgeving. In de studies van De Witte et al.,2014, VanderMeersch et al 2015 en Leslie et al (2017) bestonden de gevonden micro-plastics volledig of voor een groot deel uit vezels, en zijn in controle monsters ook vezels aangetroffen. Hoewel deze onderzoekers aangeven dat zij voor de verontreiniging van de controlemonsters corrigeerden, is uit de beschrijvingen niet altijd duidelijk wat de consequenties van deze correctie op de uiteindelijke dataset is. De werkelijke hoeveelheden plastics in mosselen en of dit werkelijk tussen monsters verschilt als de studies doen vermoeden, is daardoor nog niet goed vast te stellen. 
Tabel 4

Hoeveelheden micro-plastics in consumptie mosselen uit de handel en in het wild verzamelde mosselen.

\begin{tabular}{|c|c|c|c|c|c|c|}
\hline \multirow[t]{2}{*}{ Mossel } & \multicolumn{3}{|c|}{ Plastics per gram ww } & \multirow[t]{2}{*}{$\begin{array}{l}\text { Aandeel } \\
\text { vezels }\end{array}$} & \multirow[t]{2}{*}{$\begin{array}{l}\text { Onder- } \\
\text { grens }\end{array}$} & \multirow[t]{2}{*}{ Referentie } \\
\hline & $\min$ & $\max$ & Gemiddeld & & & \\
\hline Consumptie & 0,16 & 0,53 & $0,34 \pm 0,26$ & $100 \%$ & $>200$ um & De Witte et al.,2014 \\
\hline Wild & 0,04 & 0,81 & $0,35 \pm 0,18$ & $100 \%$ & $>200$ um & \\
\hline $\begin{array}{l}\text { Consumptie } \\
\text { (voor depuratie) } \\
\text { Consumptie } \\
\text { (na 3d depuratie) }\end{array}$ & & & $\begin{array}{l}0,36 \pm 0,07 \\
0.24 \pm 0,07\end{array}$ & $\begin{array}{l}0 \% \\
0 \% \\
\end{array}$ & $\begin{array}{l}>5 \text { um } \\
>5 \text { um }\end{array}$ & $\begin{array}{l}\text { Van Cauwenberghe et } \\
\text { al.,2014 }\end{array}$ \\
\hline Wild & 0,05 & 0,35 & $0,14 \pm 0,11$ & $0-100 \%$ & $>10$ um & Vandermeersch et al.,2015 \\
\hline Consumptie & 0 & 0,33 & $0,14 \pm 0,14$ & $0-100 \%$ & $>10$ um & \\
\hline Wild & & & 13,65 & 'many' & $>10$ um & Leslie et al.,2017 \\
\hline Wild & & & 3,61 & 'many' & $>10$ um & \\
\hline
\end{tabular}

In het onderzoek van Van Cauwenberghe et al. (2014) zijn mosselen van dezelfde partij ook gemeten na een verblijf van 3 dagen in schoon water (depuratie). Na deze periode bleek het aantal plasticdeeltjes met 33\% te zijn verminderd. Dit laat zien dat de mossel zeer waarschijnlijk in staat is om het in het spijsverteringskanaal aanwezige plastic uit te scheiden.

\subsection{Humane risico's van micro en nano-plastics}

Op basis van de nu beschikbare literatuurgegevens kan niet worden uitgesloten dat een mens door het eten van mosselen kleine plasticdeeltjes van maximaal $40 \mu \mathrm{m}$ binnenkrijgt. Zolang deze deeltjes de darmwand niet passeren zullen zij het lichaam als elk ander niet-verteerbaar deeltje zonder gevolgen via natuurlijke weg verlaten. Micro-plastics blijken nauwelijks via de darm opgenomen te worden. Bij zoogdieren is aangetoond dat bij hele hoge blootstelling aan deeltjes kleiner dan $150 \mu \mathrm{m}$ minder dan $1 \%$ van die deeltjes vanuit de darm in het lymfesystem terecht kan komen. Tot een zekere grootte zullen zij niet in staat zijn het lymfesysteem te passeren en zullen ze via de milt worden afgevoerd. Eventuele effecten blijven beperkt tot de darm (Bouwmeester et al.,2015).

Waar precies de bovengrens ligt van (plastic)deeltjes die in de bloedbaan terecht kunnen komen is niet eenvoudig vast te stellen. Dit hangt sterk samen met de samenstelling, lading en grootte van het deeltje (Bouwmeester et al.,2009; Hollman et al.,2013). Nano-deeltjes komen ook van nature voor en de slijmvliezen in de darm en in de luchtwegen functioneren als natuurlijke barrières om te voorkomen dat deze deeltjes eenvoudig het lichaam binnendringen. In laboratoriumonderzoek is aangetoond dat nano-plastic (polystyreen) deeltjes van $50 \mathrm{~nm}$ in zoogdiercellen kunnen binnendringen en daar effecten kunnen veroorzaken, en dat hierbij de lading van de deeltjes onder andere een rol speelt (Kloet et al., 2015). Hoewel beschikbare data gering is lijkt de efficiëntie waarmee nanodeeltjes vanuit de darm in het lichaam worden opgenomen met maximaal $10 \%$ relatief laag. Over opname en effecten van nano-plastics in mensen is weinig bekend (Hollman et al.,2013, Bouwmeester et al., 2015). Van nano-deeltjes van andere materialen (veelal metalen) is wel bekend dat hoge concentraties bij zoogdieren kunnen leiden tot irritaties en ontstekingen (Hollman et al.,2013, Bundschuh et al.,2016).

Bovengenoemde gegevens zijn verkregen uit onderzoek met hele hoge blootstellingsconcentraties die bedoeld om potentiele risico's van de materialen vast te stellen. Bij hele hoge concentraties zijn de meeste stoffen en materialen schadelijk. Het is uiteindelijk de blootstellingsconcentratie die bepaaltel of er werkelijk gezondheidsrisico's bestaan. Er bestaat onder onderzoekers consensus dat er op dit moment onvoldoende inzicht bestaat in het gedrag van nano-plastics om het risico voor de mens goed in te schatten (Hollman et al.,2013; Bouwmeester et al., 2015; EFSA 2016). 


\subsection{Blootstelling via mosselen en andere bronnen}

Er bestaat op dit moment geen regelgeving/voedselveiligheidsnorm voor de aanwezigheid van plastic in voedsel (EFSA 2016).

De beschikbare literatuur suggereert dat een consumptiemossel tussen 0,1 en 13,6 microplasticdeeltjes per gram bevat (Tabel 4). Onduidelijk is of de grote spreiding aan aantal deeltjes in mosselen het gevolg is van de herkomst van de mossel of van de analyse techniek en/of welke maatregelen er in de studies tegen contaminatie met vezels vanuit de lucht zijn genomen. Van Cauwenberghe et al. (2014) berekenden een jaarlijkse consumptie tussen de 1800 en 11.000 microplastic deeltjes per persoon op basis van een gemiddelde van 0.36 deeltjes per gram mosselvlees bij een consumptie van respectievelijk 12 en 72 gram per dag (representatief voor lage en hoge consumptie volgens EFSA, 2011). Het maximale aantal ligt ruim 37 maal lager dan het maximale aantal deeltjes dat door Leslie et al. (2017) is gerapporteerd. Dit betreft micro-plastic deeltjes tussen 5 en $40 \mu \mathrm{m}$. Deze deeltjes zijn over het algemeen te groot om celmembranen te passeren, maar een klein deel kan mogelijk wel cellagen passeren en in de bloedbaan terecht komen. Zij komen dan in het lymfesysteem terecht en zullen via de milt worden afgevoerd. Of dit tot negatieve effecten leidt $t_{L}$ is niet bekend (Bouwmeester et al., 2015).

Een substantieel deel van de plastic deeltjes die in mosselen zijn gevonden bestaat uit synthetische vezels. Synthetische vezels zijn ook in huisstof aanwezig (afkomstig uit kleding en stoffering). In een eerste, zeer recent onderzoek werden binnenshuis tussen 1 en 60 vezels per $\mathrm{m}^{3}$ lucht aangetroffen. Buitenshuis varieerde dit tussen 0,3 en $1,5 / \mathrm{m}^{3}$. Ongeveer één derde van de vezels bestond uit synthetisch materiaal (Dris et al. 2017).

Hoewel dit voor zover ons bekend nooit is bepaald, is het aannemelijk dat de mens via de lucht ook deze vezels binnen krijgt. Om de longen te beschermen wordt ingeademd stof, door slijmvliezen in de luchtwegen afgevangen. De vezels worden met het slijm via het spijsverteringskanaal afgevoerd. Dit is een continu proces. In een zeer recente globale schatting van het RIVM werd gesteld dat kinderen dagelijks door het 'eten' van huisstof tussen 6.000 en 22.000 synthetische vezels binnen krijgen (RIVM 2017). Dit ligt in dezelfde orde van grootte als de 11.000 micro-plastic deeltjes die een mens op jaarbasis volgens van Cauwenberghe et al. (2014) maximaal binnenkrijgt door consumptie van mosselen. Uitgaande van deze schattingen draagt het eten van mosselen nauwelijks bij aan de blootstelling van een mens aan micro-plastics.

Hetzelfde geldt hoogstwaarschijnlijk voor nano-plastics. Omdat technieken ontbreken om de aanwezigheid vast te stellen in het milieu (en dus ook in mosselen) is niet bekend in welke hoeveelheden en via welke wegen de mens aan deze kleine deeltjes wordt blootgesteld. Blootstelling kan in principe lopen via de lucht, water en elk voedsel.

Doordat een consument per mosselmaaltijd slechts een hele kleine hoeveelheid plastic binnenkrijgt (maximaal $7 \mu \mathrm{g}$; ESFA 2016) en omdat verontreinigende stoffen in grotere mate via andere dieetcomponenten worden opgenomen, bestaat er geen reëel risico voor effecten van chemische stoffen die uit deze plastics zouden vrijkomen (ESFA 2016). 


\section{Conclusie}

Plastic is wijd verspreid in het milieu aanwezig, en wordt in verschillende formaten aangetroffen op land en in zoet- en zoutwater, in sedimenten en in organismen. Bovendien is aangetoond dat ook in (binnenhuis)lucht en huisstof hele kleine plastic vezels aanwezig zijn.

In een zeer recente globale schatting van het RIVM werd gesteld dat kinderen dagelijks tussen 6.000 en 22.000 synthetische vezels binnen krijgen door het 'eten' van huisstof (RIVM 2017). Dit ligt in dezelfde orde van grootte als de 11.000 micro-plastic deeltjes die een mens op jaarbasis volgens van Cauwenberghe et al. (2014) maximaal binnenkrijgt door consumptie van mosselen. Uitgaande van deze schattingen draagt het eten van mosselen dus nauwelijks bij aan de blootstelling van een mens aan micro-plastics.

$\mathrm{Er}$ is geen aanleiding te veronderstellen dat de plastic deeltjes in het formaat dat een mossel direct uit water kan filteren (tussen de 5 en $40 \mu \mathrm{m}$ ) een gezondheidsrisico opleveren voor de consument. De meerderheid van deze deeltjes zal het lichaam op natuurlijke weg als onverteerbaar materiaal verlaten. Ook in de mossel zullen ze in het maagdarmkanaal blijven en kunnen tijdens het verwateren van consumptiemosselen worden uitgepoept.

Met de huidige technieken is het niet mogelijk om de aanwezigheid van nog kleinere plastic deeltjes (nano-plastics) aan te tonen. Dit geldt naast mosselen ook voor andere voedselbronnen, (drink)water en lucht waar zij ook verwacht kunnen worden. Over gezondheidseffecten van deze nano-plastics voor mensen is weinig bekend.

Omdat er door verschillende onderzoekers verschillende methoden worden gehanteerd is niet duidelijk hoe de gerapporteerde verschillen tussen mosselen die variëren van 0,1 tot 13 plastic deeltjes per gram vlees geïnterpreteerd moeten worden. Bovendien is niet uit te sluiten dat in een aantal gevallen verontreiniging van de monsters met synthetische vezels uit de lucht een rol heeft gespeeld.

$\mathrm{Er}$ is echter geen reden om aan te nemen dat consumptie van mosselen als onderdeel van een normaal menu een substantiële bijdrage zal leveren aan de blootstelling aan micro- en eventueel nano-plastics ten opzichte van andere voedselbronnen, lucht en water. 


\section{Samenvatting in vraag en antwoord}

\subsection{Geschiedenis fabricage en gebruik van plastic}

De grootschalige productie van plastics is vooral na de Tweede Wereldoorlog op gang gekomen en is sindsdien wereldwijd gestegen tot meer dan 300 miljoen ton per jaar (gegevens 2013 en 2015 in EPA 2016). Plastic is een verzamelnaam voor materialen bestaande uit polymeren met als basis grondstof aardolie. Doordat er verschillende soorten plastics kunnen worden geproduceerd met specifieke eigenschappen, en omdat de productie van plastics relatief goedkoop is, is het niet verwonderlijk dat deze materialen op zeer grote schaal worden geproduceerd en gebruikt.

Recentelijk worden ook plastics uit andere, veelal plantaardige materialen geproduceerd. In sommige gevallen mogen deze plastics aangemerkt worden als biologisch afbreekbaar omdat ze in composteerinstallaties kunnen worden afgebroken. In deze installaties zijn de omstandigheden optimaal, zo wordt bijvoorbeeld een temperatuur van rond $60^{\circ} \mathrm{C}$ gehandhaafd. Onder natuurlijke omstandigheden, zoals in zee, is de afbreekbaarheid ook van deze plastics echter zeer beperkt (Nauendorf et al., 2016).

\subsection{Wat zijn de belangrijkste bronnen van plastics in het milieu?}

Een belangrijk deel van de van plastic geproduceerde producten wordt maar kort gebruikt als verpakkingsmateriaal of wegwerpartikel, waardoor plastic een substantieel deel vormt van het huishoudelijk afval. Omdat niet al het afval effectief wordt verzameld en verwerkt komt er ook veel in het milieu terecht. Getransporteerd door de wind of via rivieren, eindigt een deel hiervan in zee.

Plastic pellets met een diameter tussen de 1 en $5 \mathrm{~mm}$ zijn de grondstof voor de plastic-verwerkende industrie. Deze pellets worden met regelmaat in het milieu aangetroffen (EPA, 2016). Daarnaast worden plastic deeltjes, de zogenaamde microbeads $(<1 \mathrm{~mm})$, verwerkt in verschillende verzorgingsproducten. Ook komen kunststof vezels vrij bij het wassen van kleding. Rioolwaterzuiveringen worden daarom als potentiele bron gezien voor micro-plastics in het oppervlaktewater. In hoeverre deze een belangrijke bron vormen is nog niet goed onderzocht. Resultaten van uitgevoerde onderzoeken lopen tevens sterk uiteen, van $<1 / \mathrm{m}^{3}$ (Carr el al.,2016) tot $51000-81000 / \mathrm{m}^{3}$ (Leslie et al., 2017). De reden van deze enorme verschillen is onduidelijk. Het kan het gevolg zijn van verschillen tussen de onderzochte rioolwaterzuiveringen en/of in de (kwaliteit van de) verwerkingsmethoden van de monsters.

Van de plasticdeeltjes die in het oppervlaktewater terecht komen zal naar verwachting een deel in het slib van het binnenwater bezinken (Besseling, et al., 2017a). De rest kan uiteindelijk de zee bereiken. Naast bovengenoemde bronnen vormen in het zoutwater milieu zelf nylon visnetten een belangrijke bron van plastic, zowel door verlies als door afslijten van fragmenten tijdens het gebruik in de bodemvisserij (http://www.vispluisvrij.nl).

Volgens een ruwe schatting komt er jaarlijks tussen de 5 en 13 miljoen ton plastic in zee terecht, afkomstig van allerlei bronnen wereldwijd (gebaseerd op schatting voor 2010 Jambeck et al., 2015, in EPA, 2016). 


\subsection{Uit welke materialen bestaan deze plastics?}

De meest typen plastic en hun vormen, die in zee zijn aangetroffen, zijn weergegeven in Tabel 5.

\section{Tabel 5}

Overzicht van de meeste, in zee aangetroffen typen plastics en enkele specifieke toepassingen (o.b.v. Hidalgo-Ruz et al.,2012 en Andrady 2012).

\begin{tabular}{|l|l|}
\hline Soort plastic & Bekende toepassingen \\
\hline Polyethyleen & Verpakkingsmateriaal \\
Polypropyleen & Touw, flessendoppen, microbeads/pellets \\
Polystyreen & Verpakkingsmateriaal, isolatiemateriaal, rietjes, wegwerp \\
Polyamide (nylon) & bekers \\
Polyester & Touw, visnetten \\
Acryl & Kleding, glass-fiber constructies \\
Polyvinyl chloride (PVC) & Kleding (vezels) \\
Polyethyleen terephtalate (PET) & Pijpleidingen, opslagvaten \\
\hline
\end{tabular}

\subsection{Wat is bekend over de aanwezigheid van plastics in lucht?}

Synthetische vezels in huisstof, afkomstig van kleding, stoffering en meubels, vallen ook onder de noemer 'micro-plastics'. Zeer recent zijn voor het eerst concentraties van vezels in de lucht bepaald (Dris et al 2017). Binnenshuis werden tussen 1 en 60 vezels per $\mathrm{m}^{3}$ aangetroffen en buitenshuis varieerde dit tussen 0,3 en 1,5 . Ongeveer één derde van de vezels bestond uit synthetisch materiaal.

\subsection{Wat is bekend over de aanwezigheid van plastics in zee?}

De hoeveelheid microplastics in zeewater worden veelal gerapporteerd in aantal per $\mathrm{m}^{3}$ of, wanneer het oppervlaktemonsters betreft, in aantallen per $\mathrm{km}^{2}$. In Tabel 6 zijn de beschikbare gegevens samengevat. Ter indicatie zijn gegevens per $\mathrm{km}^{2}$ omgerekend naar aantallen per $\mathrm{m}^{3}$, waarbij ervan uitgegaan is dat er standaard een laagdiepte van $10 \mathrm{~cm}$ is bemonsterd. Op het merendeel van de locaties wordt minder dan 1 micro-plastic deeltje per $\mathrm{m}^{3}$ water aangetroffen.

Hogere concentraties van 14 (gerapporteerd als $\mathrm{n} / \mathrm{m}^{3}$ ), 9,7 en 3,2 (beiden gerapporteerd als $\mathrm{n} / \mathrm{km}^{2}$ ) werden gemeten in gebieden die bekend staan als verzamelplaats van plastics. Een opvallende uitschieter vormt de dataset van Desforges et al.,(2014) die meer dan 9000 plastic deeltjes per $\mathrm{m}^{3}$ aantroffen in de North Eastern Pacific, in een zogenaamde 'gyre' waarin organisch materiaal en plastic 'gevangen' zit in een ronddraaiende stroming. Hierbij werd een echter een fijner net (65 micrometer) gebruikt dan bij de andere studies (doorgaans ca 300 micrometer). Dit suggereert dat kleinere plastic deeltjes in grotere aantallen aanwezig zijn. Er zijn echter geen gegevens bekend over de aanwezigheid van kleinere plastic deeltjes in zee (<65 micrometer), en de allerkleinste (nano)deeltjes zijn technisch nog niet aan te tonen in milieumonsters. 
Tabel 6

Maximale aantallen deeltjes micro-plastics (in elk geval $>65 \mu \mathrm{m}$ ) gerapporteerd voor verschillende regio's (gegevens uit GESAMP, 2015 aangevuld met Frias et al.,2014, Desforges et al.,2014 en Cózar et al.,2017). De datasets waarvoor alleen aantallen per $\mathrm{km} 2$ werden gerapporteerd zijn ter indicatie omgerekend naar aantallen per $\mathrm{m}^{3}$ met de aanname dat er een waterdiepte van $10 \mathrm{~cm}$ werd bemonsterd $\left(1 \mathrm{~km} 2=100.000 \mathrm{~m}^{3}\right)$.

\begin{tabular}{|c|c|c|c|}
\hline Locatie & $\mathbf{n} / \mathbf{k m}^{2}$ & $\mathbf{n} / \mathbf{m}^{3}$ & Referentie \\
\hline North Sea & Geen data & 0,05 & Thompson et al.,2004 \\
\hline Western North Atlantic & Geen data & 14,1 & Carpenter etal 1972 \\
\hline Eastern North Atlantic & Geen data & 0,116 & Collignon etal 2012 \\
\hline Mediterranean Sea & Geen data & 0,94 & Fossi et al. 2012 \\
\hline Western North Atlantic & Geen data & 0,04 & Frias et al. 2014 \\
\hline \multirow[t]{2}{*}{ North Eastern Pacific } & Geen data & 9180 & Desforges et al.,2014 \\
\hline & $\mathbf{n} / \mathbf{k m}^{2}$ & $\begin{array}{c}n / \mathbf{m}^{3} \text { berekend } \\
\text { (niet gerapporteerd) }\end{array}$ & referentie \\
\hline Western North Atlantic & 12080 & 0,12 & Carpenter \& Smith 1972 \\
\hline Western North Atlantic & 5466 & 0,05 & Colton et al.,1974 \\
\hline Western North Atlantic & 20328 & 0,20 & Law et al.2010 \\
\hline North Pacific & 34000 & 0,34 & Wong et al. 1974 \\
\hline North Pacific & 80 & 0,001 & Day and Shaw 1987 \\
\hline North Pacific & 3370 & 0,03 & Day and Shaw 1987 \\
\hline North Pacific & 96100 & 0,96 & Day and Shaw 1987 \\
\hline Eastern North Pacific & 969777 & 9,70 & Moore et al. 2001 \\
\hline Eastern North Pacific & 156800 & 1,57 & Law et al. 2014 \\
\hline Western North Pacific & 174000 & 1,74 & Yamashita \& Tanimura 2007 \\
\hline Australia & 4256 & 0,04 & Reisser et al. 2014 \\
\hline Arctic Ocean & 320000 & 3,20 & Cozar et al., 2017 \\
\hline
\end{tabular}

\subsection{Wat is het effect van plastic op de natuur?}

Afhankelijk van het formaat en de vorm kunnen macro-plastics in het milieu risico's opleveren voor organismen die erin verstrikt raken (visnetten, vislijn, verpakkingsmaterialen) of het inslikken. Dit inslikken kan onbedoeld gebeuren, zoals bij een grote filterfeeder als de bultrug (Besseling et al., 2015) waarschijnlijk het geval is, of bewust plaatsvinden, omdat het plastic als voedsel wordt gezien. Zo wordt vermoed dat zeeschildpadden plastic zakken opeten, omdat ze drijvend in het water op kwallen lijken (Fukuoka et al., 2016) en pikken Noorse Stormvogels en albatrossen drijvend plastic op van het wateroppervlak omdat ze dat waarschijnlijk voor voedsel aanzien (van Franeker en Law, 2015). Ingeslikte kleinere plastic deeltjes kunnen het lichaam via de natuurlijke weg verlaten, maar grotere stukken plastic kunnen in het maag-darmkanaal verstoppingen veroorzaken. In theorie zou een gedeeltelijk met plastic gevulde maag de eetlust kunnen remmen. In veldonderzoek zijn tweemaal correlaties aangetoond tussen de hoeveelheid in het maagdarmkanaal aanwezige plastic en de conditie (lichaamsgewicht) van zeevogels (Furness, 1985; Spear et al., 1995 in overzicht in GESAMP, 2015).

Micro-plastics zullen voor grotere organismen weinig bedreiging vormen. Zolang het maag-darmkanaal passage van de plastic deeltjes toelaat, zal het plastic het lichaam passeren als elk ander onverteerbaar deeltje. Hierbij is uiteraard de verhouding lichaamslengte en het formaat van het plastic deeltje van belang. In het algemeen zijn micro-plastics te groot om de darmwand te passeren of om via de kieuwen of longen in de bloedbaan en door het lichaam te worden verspreid. Toch suggereren laboratorium testen dat plasticdeeltjes tot $150 \mu \mathrm{m}$ groot in staat zijn cellagen te passeren (Van Cauwenberghe, 2015). Deze deeltjes, die te groot zijn om cellen binnen te dringen zijn niet in staat het lymfesysteem te passeren en worden via de milt afgevoerd (Bouwmeester et al.,2015). Dergelijke testen zijn vooral gedaan met in het laboratorium gekweekte cellen zonder de beschermende epitheliale slijmlaag die als functie heeft om grotere deeltjes af te vangen. Voor zilverdeeltjes groter dan $200 \mathrm{~nm}$ blijkt zo'n intacte slijmlaag een barrière te vormen (Georgantzopoulou et al., 2016). Of 
dit ook geldt voor plasticdeeltjes van dezelfde grootte (dus de kleinste fractie van de micro-plastics en nano-plastics) is onduidelijk en wordt verder besproken in de volgende paragraaf over nano-plastics. In laboratoriumstudies met hoge doseringen micro-plastics in de $\mu \mathrm{m}$-range zijn effecten op organismen aangetoond. Deze zijn doorgaans het gevolg van fysische reacties. Bijvoorbeeld doordat de aanwezigheid van de zwevende plastic deeltjes de effectieve voedselopname van algenetende soorten als mosselen (Van Cauwenberghe et al. 2012b, 2013a in GESAMP, 2015) en dierlijk plankton (Ogonowski et al.,2016) verminderd, of dat algengroei wordt beperkt doordat de deeltjes de doorval van licht beperken, of de algen doen samenklonteren (Zhang et al., 2017). Zonder uitzondering worden deze effecten gevonden bij concentraties die vele malen hoger liggen dan wat in het milieu tot dusverre is aangetroffen.

Dat nano-deeltjes (kleiner dan $100 \mathrm{~nm}$ ) en de kleinste fractie van micro-deeltjes (tot $200 \mathrm{~nm}$ ) celmembranen kunnen passeren en via de bloedbaan in weefsels en organen terecht kunnen komen is voor verschillende materialen aangetoond. De mate waarin dit gebeurd hangt sterk samen met de eigenschappen van de deeltjes waarbij onder andere de lading een belangrijke rol speelt. Waarschijnlijk geldt dit ook voor nano-plastic deeltjes, maar hier bestaat nog nauwelijks inzicht in (Bouwmeestsrer at al., 2015; ESFA 2016).

Opname van deze kleine plastic deeltjes in bloed en weefsel is via laboratoriumonderzoek aangetoond voor schelpdieren, kreeftachtigen en vissen (zie bijv. Koelmans et al.,2015; Da Costa 2016 voor overzichten). In sommige van deze gevallen zijn bij hoge blootstellingen ( $>0,5 \mathrm{mg} / \mathrm{L}$; Koelmans et al., 2015) ook effecten op ontwikkeling en conditie van het individu vastgesteld. Omdat concentraties aan nano-plastics in het milieu nog niet kunnen worden vastgesteld is het niet mogelijk deze laboratorium resultaten naar veldsituaties te vertalen. Nano-deeltjes gaan in het algemeen een sterke interactie aan met hun omgeving. Ze klonteren bijvoorbeeld makkelijk samen en plakken aan andere deeltjes in het water. Dit maakt het nog lastiger om resultaten van laboratoriumtesten met doorgaans minder complexe omstandigheden dan het echte milieu door te vertalen naar de veldsituatie (Bundshuh et al.,2016; Koelmans et al., 2015).

\subsection{Wat is bekend over het effect op de gezondheid van de mens?}

Op basis van de nu beschikbare literatuurgegevens kan niet worden uitgesloten dat een mens via voedsel en lucht enkele plastic deeltjes binnen krijgt. Recentelijk schatte het RIVM de opname van synthetische vezels uit huisstof door een kind dagelijks tussen 6.000 en 22.000 synthetische vezels binnenkrijgt (RIVM 2017). Ingeslikte deeltjes zullen, zolang zij de darmwand niet passeren het lichaam zonder gevolgen via natuurlijke weg verlaten als elk ander niet-verteerbaar deeltje. Microplastics blijken nauwelijks via de darm opgenomen te worden. Bij zoogdieren is aangetoond dat bij hele hoge blootstelling aan deeltjes kleiner dan $150 \mu \mathrm{m}$ minder dan $1 \%$ van die deeltjes vanuit de darm in het lymfesystem terecht kan komen. Tot een zekere grootte zullen zij niet in staat zijn het lymfesysteem te passeren en zullen ze via de milt worden afgevoerd. Eventuele effecten blijven beperkt tot de darm (Bouwmeester et al.,2015).

Waar precies de bovengrens ligt van (plastic)deeltjes die in de bloedbaan terecht kunnen komen is niet eenvoudig vast te stellen. Dit hangt sterk samen met de samenstelling, lading en grootte van het deeltje (Bouwmeester et al.,2009; Hollman et al.,2013). Nano-deeltjes komen ook van nature voor en de slijmvliezen in de darm en in de luchtwegen functioneren als natuurlijke barrières om te voorkomen dat deze deeltjes eenvoudig het lichaam binnendringen. Er bestaat onder onderzoekers consensus dat er op dit moment onvoldoende inzicht bestaat in het gedrag van nano-plastics om het risico voor de mens goed in te schatten (Hollman et al.,2013; Bouwmeester et al., 2015; EFSA 2016).

\subsection{Wat is bekend over de aanwezigheid van plastics in mosselen?}

Berichten over plastics in mosselen betreffen altijd micro-plastics. Over de aanwezigheid van nanoplastics in mosselen is om eerder genoemde redenen niets bekend, en macro-plastics zijn te groot om door een mossel te worden opgenomen. 
Drie Belgische studies (De Witte et al.,2014, Van Cauwenberghe et al.,2014 en VanderMeersch et al 2015) geven zeer overeenkomstige resultaten met tussen 0,1 en 0,4 micro-plastic deeltje per gram mosselvlees zonder verschil tussen wilde en consumptiemosselen (Tabel 7).

In een onderzoek door Leslie et al.,2017 zijn ruim 40 maal hogere aantallen deeltjes in wilde mosselen gevonden. Het is onduidelijk in hoeverre deze verschillen het gevolg zijn van een verschil in analysemethode. Het feit dat Leslie et al. (2017) meer deeltjes vindt dan De Witte et al. (2014) kan worden veroorzaakt doordat de laatstgenoemde deeltjes kleiner dan $200 \mu \mathrm{m}$ niet onderzocht, terwijl Leslie et al. (2017) een ondergrens van $5 \mu \mathrm{m}$ hanteerde. VanderMeersch et al (2015) en Van Cauwenberghe et al.,(2014) hanteerden een vergelijkbare ondergrens als Leslie et al.(2017). Van Cauwenberghe et al.,(2014) gebruikten een agressieve destructiemethode, waarvan zij aangeven dat hierdoor mogelijk nylonvezels zijn afgebroken. Het feit dat zij geen vezels in hun (blanco) monsters aantreffen zou hier ook op kunnen wijzen, maar kan evengoed duiden op een goede preventie van contaminatie vanuit de werkomgeving. In de studies van De Witte et al.,2014, VanderMeersch et al 2015 en Leslie et al (2017) bestonden de gevonden micro-plastics volledig of voor een groot deel uit vezels, en zijn in controle monsters ook vezels aangetroffen. Hoewel deze onderzoekers aangeven dat zij voor de verontreiniging van de controlemonsters corrigeerden, is uit de beschrijvingen niet altijd duidelijk wat de consequenties van deze correctie op de uiteindelijke dataset is. De werkelijke hoeveelheden plastics in mosselen en of dit werkelijk tussen monsters verschilt als de studies doen vermoeden, is daardoor nog niet goed vast te stellen.

\section{Tabel 7}

Hoeveelheden micro-plastics in consumptie mosselen uit de handel en in het wild verzamelde mosselen.

\begin{tabular}{|c|c|c|c|c|c|c|}
\hline \multirow[t]{2}{*}{ Mossel } & \multicolumn{3}{|c|}{ Plastics per gram ww } & \multirow[t]{2}{*}{$\begin{array}{c}\text { Aandeel } \\
\text { vezels }\end{array}$} & \multirow[t]{2}{*}{$\begin{array}{l}\text { Onder- } \\
\text { grens }\end{array}$} & \multirow[t]{2}{*}{ Referentie } \\
\hline & $\min$ & $\max$ & Gemiddeld & & & \\
\hline Consumptie & 0,16 & 0,53 & $0,34 \pm 0,26$ & $100 \%$ & $>200$ um & De Witte et al.,2014 \\
\hline Wild & 0,04 & 0,81 & $0,35 \pm 0,18$ & $100 \%$ & $>200$ um & \\
\hline $\begin{array}{l}\text { Consumptie } \\
\text { (voor depuratie) }\end{array}$ & & & $0,36 \pm 0,07$ & & & $\begin{array}{l}\text { Van Cauwenberghe et } \\
\text { al.,2014 }\end{array}$ \\
\hline $\begin{array}{l}\text { Consumptie } \\
\text { (na } 3 d \text { depuratie) }\end{array}$ & & & $0.25 \pm 0,07$ & $0 \%$ & $>5$ um & \\
\hline Wild & 0,05 & 0,35 & $0,14 \pm 0,11$ & $0-100 \%$ & $>5$ um & Vandermeersch et al.,2015 \\
\hline Consumptie & 0 & 0,33 & $0,14 \pm 0,14$ & $0-100 \%$ & $>5$ um & \\
\hline Wild & & & 13,65 & 'many' & $>10$ um & Leslie et al.,2017 \\
\hline Wild & & & 3,61 & 'many' & $>10$ um & \\
\hline
\end{tabular}

\subsection{Hoe worden plastics opgenomen door mosselen en worden ze ook weer uitgescheiden?}

Een mossel verzamelt voedsel door algen uit het water te filteren. Een gezonde mossel kan meer dan een liter water per uur filtreren, waarbij met grote efficiëntie deeltjes tussen 5 en 40 micrometer worden verzameld. Micro-plastics van deze grootte in het water zullen dus door een mossel uit het water worden verzameld, samen met algen en bijvoorbeeld in het water aanwezig slib.

Om te kunnen overleven in slibrijk water is een mossel tot op zekere hoogte in staat om uit het verzamelde materiaal eetbare van oneetbare deeltjes te scheiden. De als niet-eetbaar herkende delen worden niet door de mossel ingeslikt, maar als 'pseudo-faeces' uitgescheiden. Aangenomen mag worden dat dit ook met (een deel van) de door de mossel opgenomen micro-plastics zal gebeuren. Onverteerbare delen van het opgenomen voedsel verlaten een mossel na passage van het maagdarmkanaal als faeces. Dit gebeurt bijvoorbeeld met slibdeeltjes bij het verwateren van mosselen. Omdat de filterefficiëntie van een mossel snel afneemt bij deeltjes kleiner dan $4 \mu \mathrm{m}$ zullen individuele nano-plasticdeeltjes door een mossel niet worden verzameld. Nano-deeltjes die zijn samengeklonterd tussen 5 en 40 micrometer kan de mossel wel uit het water filteren (Matson et al., 2015). In een laboratoriumstudie met hoge gehalten nano-plastics bleken de mosselen deze geklonterde nano- 
deeltjes als pseudo-faeces uit te scheiden (Wegner et al., 2012). Dit betrof 'verse' nano-plastics. Samenklontering met algen of bacteriën zou er voor kunnen zorgen dat de mossel de nano-deeltjes niet als oneetbaar herkend en als voedsel tot zich neemt.

\subsection{Kunnen mosselen plastics kwijtraken door verwateren (depuratie)?}

In het onderzoek van Van Cauwenberghe et al. (2014) zijn hoeveelheden plasticdeeltjes in mosselen gemeten voor en na een verblijf van 3 dagen in schoon water (depuratie). Na deze periode bleek het aantal plasticdeeltjes met 33\% te zijn verminderd. Dit laat zien dat de mossel zeer waarschijnlijk in staat is om in elk geval de in het spijsverteringskanaal aanwezige plastic deeltjes uit te scheiden.

\subsection{Wat is het risico dat plastics uit geconsumeerde mosselen de darmwand van de mens passeren?}

Mosselen filteren het meest efficiënt deeltjes tussen 5 en 40 micrometer uit het water, maar zouden kunnen ook geklonterde kleinere (nano)deeltjes kunnen opnemen. Met de huidige technieken is het nog niet mogelijk om de aanwezigheid van deze extreem kleine plastic deeltjes in mosselen aan te tonen. Deze nano-deeltjes worden in staat geacht de darmwand te passeren en via de bloedbaan in celweefsel terecht te komen. Waar precies de bovengrens ligt van (plastic)deeltjes die in de bloedbaan terecht kunnen komen is niet eenvoudig vast te stellen. Dit hangt sterk samen met de samenstelling, lading en grootte van het deeltje (Bouwmeester et al.,2009; Hollman et al.,2013).

\subsection{Wat is het risico voor human health als mosselen met plastics worden geconsumeerd (expert judgement)?}

Omdat er door verschillende onderzoekers verschillende methoden worden gehanteerd is niet duidelijk hoe de gerapporteerde verschillen tussen mosselen die variëren van 0,1 tot 13 plastic deeltjes per gram vlees geïnterpreteerd moeten worden. Er is geen aanleiding te veronderstellen dat de plastic deeltjes in het formaat dat een mossel direct uit water kan filteren (tussen de 5 en $40 \mu \mathrm{m}$ ) een gezondheidsrisico opleveren voor de consument. De meerderheid van deze deeltjes zal het lichaam op natuurlijke weg als onverteerbaar materiaal verlaten. Ook in de mossel zullen ze in het maagdarmkanaal blijven en kunnen tijdens het verwateren van consumptiemosselen worden uitgepoept. Bovendien is niet waarschijnlijk dat het af en toe eten van een portie mosselen een substantiële bijdrage zal leveren de hoeveelheid microplastics die een mens via andere wegen binnen krijgt. In een zeer recente globale schatting van het RIVM werd gesteld dat kinderen dagelijks door het 'eten' van huisstof tussen 6.000 en 22.000 synthetische vezels binnen krijgen, eventuele inname via de ademhaling is hierbij niet meegenomen (RIVM 2017). Dit ligt in dezelfde orde van grootte als de 11.000 micro-plastic deeltjes die een mens op jaarbasis volgens van Cauwenberghe et al. (2014) maximaal binnenkrijgt door consumptie van mosselen. Uitgaande van deze schattingen draagt het eten van mosselen nauwelijks bij aan de blootstelling van een mens aan micro-plastics.

Naast microplastics kan een mossel ook kleinere (nano) plastic deeltjes uit het water filteren als deze geklonterd zijn met bijvoorbeeld algen of bacteriën. Over de effecten van deze nano-plastics in mensen is weinig bekend. Met de huidige technieken is het ook nog niet mogelijk om de aanwezigheid van deze extreem kleine plastic deeltjes in mosselen aan te tonen. Dit geldt ook voor andere voedselbronnen, (drink)water en lucht, maar als zij in mosselen aanwezig zijn, dan kunnen ze ook daar verwacht worden. $\mathrm{Er}$ is daarom geen reden om aan te nemen dat consumptie van mosselen als onderdeel van een normaal menu een substantiële bijdrage zal leveren aan de blootstelling aan nanoplastics ten opzichte van andere bronnen. 


\section{$7 \quad$ Referenties}

Besseling E., Foekema E.M., Van Franeker J.A., Leopold M.F., Kuhn S., Rebolledo E.L.B., Hesse E., Mielke L., IJzer J., Kamminga P., Koelmans A.A. (2015): Microplastic in a macro filter feeder: Humpback whale Megaptera novaeangliae. Marine Pollution Bulletin 95, 248-252.

Besseling, E., Quik, J.T.K., Sun, M., Koelmans, A.A., 2017a. Fate of nano- and microplastic in freshwater systems: A modeling study. Environmental Pollution 220, 540-548.

Besseling E., Foekema E.M., Van Den Heuvel-Greve M.J., Koelmans A.A. (2017b):The effect of microplastic on the uptake of chemicals by the lugworm Arenicola marina (L.) under environmentally relevant exposure conditions. Environ. Sci. Technol., in press DOI: 10.1021/acs.est.7b02286

Bouwmeester H.; Dekkers S.; Noordam M. Y., Hagens W.I., Bulder A. S., de Heer C., ten Voorde S.E.C.G., Wijnhoven S.W.P., Marvin H.J.P., Sips A.J.A.M. (2009): Review of health safety aspects of nanotechnologies in food production. Regul. Toxicol. Pharmacol. 2009, 53 (1), 52-62.

Bouwmeester H, Hollman PCH, Peters RJB (2015): Potential Health Impact of Environmentally Released Micro- and Nanoplastics in the Human Food Production Chain: Experiences from Nanotoxicology. Environ. Sci. Technol. 2015, 49, 8932-8947

Bundschuh M, Seitz F, Rosenfeldt RR, Schulz R (2016): Effects of nanoparticles in fresh waters: risks, mechanisms and interactions. Freshwater Biology (2016) 61, 2185-2196

Carr SA, Liu J, Tesoro AG (2016): Transport and fate of microplastic particles in wastewater treatment plants. Water Research 91 (2016) 174e182

Cózar A., Martí E., Duarte C.M., García-de-Lomas J., Sebille E. van, Ballatore T.J., Eguíluz V.M., González-Gordillo J.I., Pedrotti M.L., Echevarría F., Troublè R., Irigoien X. (2017): The Arctic Ocean as a dead end for floating plastics in the North Atlantic branch of the Thermohaline Circulation. Sci. Adv. 2017;3: e1600582 19 April 2017

Da Costa JP, Santos PSM, Duarte AC, Rocha-Santos T (2016): (Nano)plastics in the environment Sources, fates and effects. Science of the Total Environment 566-567 (2016) 15-26

De Witte, B.,Devriese, L.,Bekaert, K.,Hoffman, S.,Vandermeersch, G., Cooreman, K., Robbens, J. (2014): Quality assessment of the blue mussel (Mytilus edulis): Comparison between commercial and wild types. Marine pollution bulletin Vol 85, 1, 146-155

Desforges J.-P.W., Galbraith M., Dangerfield N., Ross P.S. (2014): Widespread distribution of microplastics in subsurface seawater, in the NE Pacific Ocean Marine Pollution Bulletin 79 (2014) 9499

Dris, R., Gasperi, J., Mirande, C., Mandin, C., Guerrouache, M., Langlois, V., Tassin, B. (2017) A first overview of textile fibers, including microplastics, in indoor and outdoor environments Environmental Pollution, 221, pp. 453-458.

EFSA (2011): Use of the EFSA comprehensive European food consumption database in exposure assessment. European Food Safety Authority EFSA J. 9, 2097.

EFSA (2016): Presence of micro-plastics and nano-plastics in food, with particular focus on seafood. EFSA Panel on Contaminants in the Food Chain (CONTAM). EFSA Journal 2016;14(6):4501

EPA (2016): State of the Science White Paper. A Summary of Literature on the Chemical Toxicity of Plastics Pollution to Aquatic Life and Aquatic-Dependent Wildlife. U.S. Environmental Protection Agency Office of Water Office of Science and Technology Health and Ecological Criteria Division. https://www.epa.gov/wqc/aquatic-life-ambient-water-quality-criteria.

Frias, J., Otero, V., Sobral, P., 2014. Evidence of microplastics in samples of zooplankton from Portuguese coastal waters. Marine Environmental Research 95, 89-95.

Takuya F, Misaki Y, Chihiro K, et al.,(2016): The feeding habit of sea turtles influences their reaction to artificial marine debris. SCIENTIFIC REPORTS, Vol: 6, 28015.

Georgantzopoulou, A., Serchi, T., Cambier, S., Leclercq, C.C., Renaut, J., Shao, J., Kruszewski, M., Lentzen, E., Grysan, P., Eswara, S., Audinot, J.N., Contal, S., Ziebel, J., Guignard, C., Hoffmann, L., Murk, A.J., Gutleb, A.C., 2016. Effects of silver nanoparticles and ions on a coculture model for the gastrointestinal epithelium. Particle and Fibre Toxicology 13.

GESAMP (2015): "Sources, fate and effects of microplastics in the marine environment: a global assessment" (Kershaw, P. J., ed.). Rep. Stud. GESAMP No. 90, 96 p.

Hermsen E; Pompe R; Besseling E; Koelmans A (2017): Detection of low numbers of microplastics in North Sea fish using strict quality assurance criteria. Marine poll bul. In press.

https://doi.org/10.1016/j.marpolbul.2017.06.051 
Hidalgo-Ruz, V., Gutow, L., Thompson, R.C., Thiel, M., 2012. Microplastics in the Marine Environment: A Review of the Methods Used for Identification and Quantification. Environmental Science \& Technology 46, 3060-3075.

Hollman P.C.H., Bouwmeester H., Peters R.J. (2013): Microplastics in the aquatic food chain: Sources, measurements, occurrence and potential health risks. RIKILT report 2013.003

Kloet S.K., Walczak A.P., Louisse J., van den Berg H.H.J., Bouwmeester H., Tromp P., Fokkink R.G., Rietjens I.M.C.M. (2015): Translocation of positively and negatively charged polystyrene nanoparticles in an in vitro placental model. Toxicology in Vitro, Vol 29, Issue 7

Koelmans A.A., Besseling E., Shim W.J. (2015): Nano-plastics in the aquatic environment. Critical Review. In: Bergmann M, Gutow L, Klages M (eds) Marine Anthropogenic Litter. Springer, Berlin, ISBN 978-3-319-16510-3, p 325-340.

Koelmans, A.A., Adil Bakir, G. Allen Burton, and Colin R. Janssen (2016): Microplastic as a Vector for Chemicals in the Aquatic Environment: Critical Review and Model-Supported Reinterpretation of Empirical Studies. Environ. Sci. Technol., 2016, 50 (7), pp 3315-3326

Leslie H.A., Brandsma S.H., van Velzen M.J.M., Vethaak A.D.(2017): Microplastics en route: Field measurements in the Dutch river delta and Amsterdam canals, wastewater treatment plants, North Sea sediments and biota. Environment International 101 (2017) 133-142

Nauendorf A, Krause S, Bigalke N K, Gorb E V, Gorb S N, Haeckel M, Wahl M, Treude T (2016): Microbial colonization and degradation of polyethylene and biodegradable plastic bags in temperate fine-grained organic-rich marine sediments. Marine Pollution Bulletin Vol 103, Issues 1-2, Pages 168-178

Ogata et al.,2009: International Pellet Watch: Global monitoring of persistent organic pollutants (POPs) in coastal waters. 1. Initial phase data on PCBs, DDTs, and HCHs. Marine Pollution Bulletin, Volume 58, Issue 10, 2009, 1437 - 1446

Ogonowski M., Schür C., Jarsén A., Gorokhova E. (2016): The Effects of Natural and Anthropogenic Microparticles on Individual Fitness in Daphnia magna. PLOS ONE DOI: 10.1371/journal.pone.0155063 May 13, 20161

Rippen A.D., Foekema E.M. (2012): Analysis of available data on marine litter as subcontractor in ENV.D.2/ETU/2011/0043. Wageningen IMARES report 2012

RIVM (2017): Nieuwsbrief microplastics 1 juni 2017. Rijksinstituut voor Volksgezondheid en Milieu Centrum voor Veligheid van Stoffen en Producten, Bilthoven

Torre M., Digka N, Anastasopoulou A, Tsangaris C, Mytilineou C. (2016): Anthropogenic microfibres pollution in marine biota. A new and simple methodology to minimize airborne contamination. Marine Pollution Bulletin 113 (2016) 55-61

Vandermeersch G, VanCauwenberghe L, Janssen C, Marques A, Granby K, Fait G, Kotterman M, Diogène J, Bekaert K, Robbens J, Devriese L (2015): A critical view on microplastic quantification in aquatic organisms. EnvironmentalResearch143(2015)46-55

Van Cauwenberghe L., Janssen C.R. (2014): Microplastics in bivalves cultured for human consumption. Environmental Pollution 193 (2014) 65e70

Van Cauwenberghe L. (2015): Occurrence, effects and risks of marine microplastics. Chapter 7. PhDThesis Ghent University, Ghent, Belgium.

van Franeker J.A., Law K.L. (2015): Seabirds, gyres and global trends in plastic pollution. Environmental pollution. Vol. 203. Page 89 - 96.

Wegner, A., Besseling, E., Foekema, E.M., Kamermans, P., Koelmans, A.A., 2012. Effects of nanopolystyrene on the feeding behavior of the blue mussel (Mytilus edulis L.). Environmental Toxicology and Chemistry 31, 2490-2497.

Zhang C., Chen X., Wang J., Tan L. (2017): Toxic effects of micro-plastic on marine microalgae Skeletonema costatum: Interactions between micro-plastic and algae. Environmental Pollution 220 (2017)

Ziccardi, L.M., Edgington, A., Hentz, K., Kulacki, K.J., Driscoll, S.K., 2016. Microplastics as vectors for bioaccumulation of hydrophobic organic chemicals in the marine environment: A state-of-thescience review. Environmental Toxicology and Chemistry 35, 1667-1676. 


\title{
$8 \quad$ Kwaliteitsborging
}

Wageningen Marine Research beschikt over een ISO 9001:2008 gecertificeerd kwaliteitsmanagementsysteem (certificaatnummer: 187378-2015-AQ-NLD-RvA). Dit certificaat is geldig tot 15 september 2018. De organisatie is gecertificeerd sinds 27 februari 2001. De certificering is uitgevoerd door DNV Certification B.V.

\section{Verantwoording}

\author{
Rapport C055/17
}

Projectnummer: 431.32000.06-03

Dit rapport is met grote zorgvuldigheid tot stand gekomen. De wetenschappelijke kwaliteit is intern getoetst door een collega-onderzoeker en het verantwoordelijk lid van het managementteam van Wageningen Marine Research

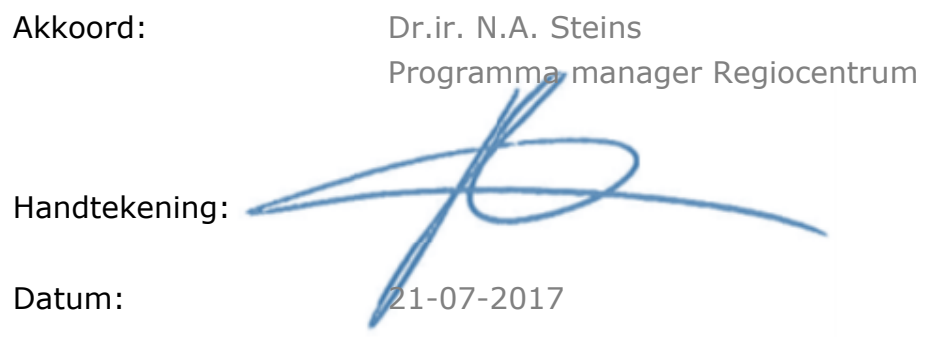

Akkoord:

Drs. J. Asjes

Manager Integratie

Handtekening:

Datum: 
Wageningen Marine Research

T: +31(0)317480900

E: marine-research@wur.nl

www.wur.nl/marine-research

Visitors address

- Ankerpark 271781 AG Den Helder

- Korringaweg 7, 4401 NT Yerseke

- Haringkade 1, 1976 CP IJmuiden
Wageningen Marine Research is the Netherlands research institute established to provide the scientific support that is essential for developing policies and innovation in respect of the marine environment, fishery activities, aquaculture and the maritime sector.

Wageningen University \& Research is specialised in the domain of healthy food and living environment.

The Wageningen Marine Research vision:

'To explore the potential of marine nature to improve the quality of life.'

The Wageningen Marine Research mission

- To conduct research with the aim of acquiring knowledge and offering advice on the sustainable management and use of marine and coastal areas.

- Wageningen Marine Research is an independent, leading scientific research institute.

Wageningen Marine Research is part of the international knowledge organisation Wageningen UR (University \& Research centre). Within Wageningen UR, nine specialised research institutes of Stichting Wageningen Research (a Foundation) have joined forces with Wageningen University to help answer the most important questions in the domain of healthy food and living environment. 